\title{
坤甸华人零零后对春节习俗和忌讳的认识研究
}

\section{PEMAHAMAN DAN PANDANGAN KAUM MILENIAL TIONGHUA PONTIANAK \\ TERHADAP PANTANGAN PADA TRADISI IMLEK}

Lysa Lho（何利冰）

Sekolah Tinggi Bahasa Harapan Bersama

Emai1:1ysa_ho@foxmail.com

\begin{abstract}
摘要
中华文化有着强大的向心力, 这种向心力使得海外华人乃至华人的子孙对中华文化 都有着极强的认同感, 无论身处何地都会不由自主地遵循中华文化中对于自己为人处事 的要求。在中华文化的节庆中，春节无疑是最能代表中华文化的节日，海外华人也多会 按照惯例庆祝春节。因此本文通过问卷调查来论述坤甸华人零零后对春节习俗和忌讳的 认识。从研究结果来看, 坤甸华人零零后对春节习俗和忌讳有较强的认同感但是对春节 习俗与忌讳并没有太多了解、感性认识较强, 理性认识偏弱、认识渠道单一, 主体性较 差、行为认同度较高, 持有开放态度。
\end{abstract}

关键词：坤甸华人；春节习俗与忌讳；文化认同

\section{一 引言}

\section{1 背景}

一个民族的精神文化内涵丰富, 其中节日文化是其中的重要组成部分, 也是本民族 人民产生民族认同感的重要依据。春节，作为持续时间最长，内容最丰富的节日，已经 成为中华民族最重要的节日, 更是形成了独有的节日形式和文化寓意。在中国传统文化 当中, 春节寄托了人们对新一年生活的美好祝福和愿景, 希望来年能够风调雨顺, 五谷 丰登, 同时, 随着时代的发展, 春节也被赋予了更多社会文化的功能, 传递人们的一种 社会情感。时至今日, 春节承载着丰富的传统文化内涵已经走出了国门, 传播到了海外。

中华文化具有五千年的悠长历史, 很多传统文化已经在海外得到了一定程度的传承。 以印度尼西亚 (以下简称 “印尼”) 为例, 公元 15 世纪就有文献记载有中国移民到印尼, 
现在印尼全国大约有华人上万人。由于先后经历葡萄牙、西班牙、英国、荷兰、日本等 多个国家的侵占, 殖民主义者对华侨和原住民采取的分而治之的策略使得原住民有较强 的反华情绪。同时, 外国资本伴随着殖民进程大量进入印尼, 而印尼地区在取得独立的 初期并没有认识到华人资本与外国垄断资本的不同，统治集团在面临经济危机时，为了 巩固自己的统治地位, 往往是把华侨当作替罪羊放在人民的对立面, 转移本国人民的视 线, 同样引发了人民的排华情绪, 使得当地华人所处的政治环境和社会环境举步维艰。 然而中国春节的习俗正是在这样的时代背景下，顶着歧视和压迫而被华人传承下来。

\section{2 研究对象}

本文以出生地在坤甸, 祖辈来自广东、福建两省的华人零零后作为研究对象, 对其 展开问卷调查。

\section{3 研究方法}

文献综述法: 搜索、整理及研读有关研究中国、东南亚、印尼、春节文化的论文、 期刊, 书籍等有关文献，将相关研究成果作为本研究的理论支持和借鉴方法。

调查问卷法: 对 400 位零零后的坤甸华人随机发放调查问卷, 了解他们对春节习俗 和忌讳的相关情况。

统计分析法: 使用简单的定量统计方法, 统计出相关数据, 根据统计得出的相关数 据, 进行分析并得出分析结果。

\section{4 研究意义}

当前中国国力不断增强, 借助 “一带一路” 战略, 中国正在成为世界舞台上申冉升 起的新星, 而国力的空前强大使得华人群体对中华文化的认同感进一步加深。笔者查阅 了诸多文献, 尚未发现有学者对印尼华人的春节文化认同进行过研究, 而春节文化是中 华文化的重要组成部分, 华人代系之间的交流正是凭借这样的节日纽带才能够得到进一 步强化, 因此针对坤甸华人零零后对春节习俗和忌讳的认识进行研究, 将更有助于了解 春节这样的传统节日文化是如何在坤甸华人群体中得以传承, 以及传承的现状如何, 这 是本文的理论意义所在。

与此同时，坤甸华人身上的中华文化在漫长的发展过程中同样受到了印尼文化的影 响, 这使得坤甸华人的春节习俗已经有了诸多的变化, 而这种变化实际上也是中华文化 地域适应性的一种体现, 本文针对坤甸华人零零后对春节习俗和忌讳的认识进行研究, 
从实践层面也能为印尼地区中华文化的传承与发扬提供现实的依据, 帮助印尼华人认识 到自己在文化传承方面存在的问题，这是本文的实践意义所在。

\section{二 文献综述}

\section{1 印尼华人的相关研究}

\subsection{1 印尼华人历史}

中国与印度尼西亚（简称 “印尼” ）之间的交流最早可以追溯到 15 世纪前, 当时 的唐朝就与印尼有着贸易往来, 商人沿着海上丝绸之路寻找贸易机会, 僧侣则沿着海上 丝绸之路前往印度, 甚至中国人还成为了印尼最早的伊斯兰教的传教士。最早记载的华 人大规模移民至印尼的记录发生在荷兰殖民的中期, 这一时期移民的华人大多是为了寻 找适宜的商机。然而, 欧洲人为上, 华人与阿拉伯裔为中, 而本地土著为下, 这一由荷 兰人所建立起来的社会等级制度, 是的华人与当地原住民之间一直很难亲密的融合。这 一制度的建立与荷兰希望优待个别民族而使原有的社会体制发生变化的愿望相符合。这 就使得华人成为了荷兰人进行殖民统治的有力工具, 同时还能够缓和当地土著与荷兰殖 民者之间深层次的矛盾。

在印尼独立时, 华人已经有近一千万, 占到印尼总人口的 5\%, 并且其中有九成以上 的华人已经加入了印尼的国籍。尽管印尼独立之后当地土著曾经与华人产生多种冲突, 甚至爆发了种种暴力事件, 但是随着时代的发展, 移民的华人逐渐在印尼落地生根, 成 为了当地不可或缺的一部分。当然, 中华文化也因为华人移民的存在而开始在印尼地区 逐渐繁荣 ${ }^{1}$ 。

\subsection{2 印尼华人身份认同}

2006 年以来, 有不少学者对印尼华人的身份认同进行过研究。王爱平 (2006) 认为 印尼华裔青少年均已完全认同印度尼西亚国家, 但是印尼长期推行歧视、排斥华人政策 极大地挫伤了这种感情归属。他们有着强烈的华人身份认同意识, 对融入印尼当地社会 持积极的态度, 并期望与印尼主体民族拥有同等的待遇2。黄显（2012）提出，印尼华裔

\footnotetext{
${ }^{1}$ 胡翊. 二战后印尼华人经济的发展状况、影响因素及贡献[D]. 华中师范大学, 2017.

${ }^{2}$ 王爱平. 印尼华裔青少年的身份认同与国家认同一一华侨大学华文学院 (集美)印尼华裔学生的调查 研究 $[J]$. 武汉大学学报 (哲学社会科学版), 2006 (02) :282-288.
} 
青少年有着强烈的华人身份认同意识，对融入印尼当地社会持积极的态度，并保持着对 中华传统文化的传承。印尼华裔青少年的身份认同和文化认同均是一个动态的过程, 国 家的有关法律处和政策在其中起着决定性的支配作用 ${ }^{3}$ 。沈玲（2015）提出印尼政府实行 的华人同化政策自实行以来客观上阻碍了汉语语言在家庭内部的代际传播。华人家庭各 成员的语言能力与汉语水平呈现代际变化。从印尼华人对语言、宗教、祖先、历史、族 际通婚等的态度可以看出, 新生代华裔青少年对印尼的国家认同与情感归属明确, 但他 们对自己的祖籍国中国依然怀有亲近的情感，还保留着对本民族的文化认同度，只是在 许多方面较其祖父辈相比, 认同程度有所减弱 ${ }^{4}$ 。张小倩（2016）认为印尼华人社会所出 现的 “再华化” 现象在无形中推动着中华文化软实力的传播, 同时吸引了印尼其他族群 对中华文化的兴趣和参与，有利于推动印尼族群之间的融合、印尼民主国家建设的发展 以及中国和印尼双方的进一步了解和交往 ${ }^{5}$ 。

\section{2 认同理论}

文化认同的概念在学界一直颇有争议，普遍的观点认为文化认同应该是一种对个体 对群体文化的认可和赞同，同时被群体文化所影响的感觉。每个人都是生活在集体当中， 想要使自身所接受的文化观念完全不受到社会群体的影响是不现实的，社会群体的文化 不仅仅会在观念上对个体产生影响, 更是会在生活的方方面面影响到个体的生活。当然, 集体文化多种多样, 受到集体文化的影响并不意味着一定要丢失个人的想法, 个体在实 现自我认同的过程实际上是从多样的群体文化中寻找到自己认同的文化的过程，因此个 体文化与群体文化也可以说是互相影响, 相辅相成的。亨廷顿（2002）认为对于大多数 人来说，能够做到独立的文化认同已经具有非比寻常的意义，不同民族的人之所以形成 不同的文化大多是因为他们在表示自身文化认同的时候会选择他们认为最为有意义的 实物来作为载体, 而同一民族往往选择的载体相同, 利用这一载体来实现宗教、语言、 习俗等方面的自我定义。

\section{3 小结}

总的看来，印尼华人的移民历史可以追溯至几个世纪之前，近几个世纪不断有华人 移民至印尼。由于华人群体已经形成了固定的集体文化, 而印尼华人聚集生活的方式也

\footnotetext{
3 黄暗. 印尼华裔青少年对中华文化的认同及其对汉语学习的影响 [D]. 广西师范大学, 2012.

${ }^{4}$ 沈玲. 印尼华人家庭语言使用与文化认同分析一一印尼雅加达 500 余名新生代华裔的调查研究 $[\mathrm{J}]$. 世界民族, 2015 (05) : 73-85.

${ }^{5}$ 张小倩. 二十一世纪以来印尼华人 “再华化” 现象研究 [J]. 世界民族, 2016 (01) : 82-91.
} 
使得中华文化拥有了长久留存的空间，因而春节这样一类中华文化的符号已然成为了印 尼华人文化认同的基础，成为了印尼华人与传统中华文化之间斩不断的文化血脉。

\section{三 坤甸华人零零后对春节习俗和忌讳的认识}

\section{1 调查问卷设计及实施}

为了解坤甸华人零零后对春节习俗和忌讳的认识现状, 笔者参考了文化认同的相关

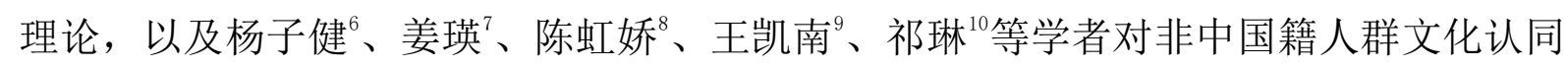
的研究问卷, 设计出了本文使用的《坤甸华人零零后对春节习俗和忌讳的认识》的调查 问卷。调查问卷基于文化认同理论设计了认知认识、情感认识、实践认识三种类型的问 题, 通过这三个层面来了解坤甸华人零零后对春节习俗和忌讳的认识现状。笔者选择华 人聚集地随机发纸质问卷, 共发放问卷 400 张, 回收有效问卷 380 张, 问卷回收有效率 95\%。其中男性受访者占比 $20.5 \%$, 女性受访者占比 $79.5 \%$, 具体调查情况如下:

\section{2 对春节习俗和忌讳有较强的认同感}

如图 1 所示, 在问及 00 后受访者是否喜欢过春节时, 表示自己非常喜欢的占比达 到了 $65.2 \%$, 表示自己一般喜欢的占比 $33 \%$, 表示不确定的占比 $1.8 \%$, 没有受访者表示 自己不喜欢或者非常不喜欢春节（见图 1)。正是因为大多数零零后受访者都喜欢春节, 在回答春节的日期这一问题上，大多数受访者才能够回答对是正月初一（见图 2)。

\footnotetext{
${ }^{6}$ 杨子健. 在邑来华留学生跨文化适应与中华文化认同的相关研究 [D]. 广西大学, 2018.

${ }^{7}$ 姜瑛. 菲律宾主流中学学生汉语学习动机与中华文化认同相关度研究 [D]. 福建师范大学, 2018.

${ }^{8}$ 陈虹娇. 南非中文专业大学生汉语学习动机与文化认同研究 [D]. 暨南大学, 2018.

9 王凯南. 日本汉语学习者的文化认同研究 [D]. 内蒙古师范大学, 2018.

${ }^{10}$ 祁琳. 泰国华裔青少年对中华文化认同及影响因素的调查研究 [D]. 山东师范大学, 2018.
} 


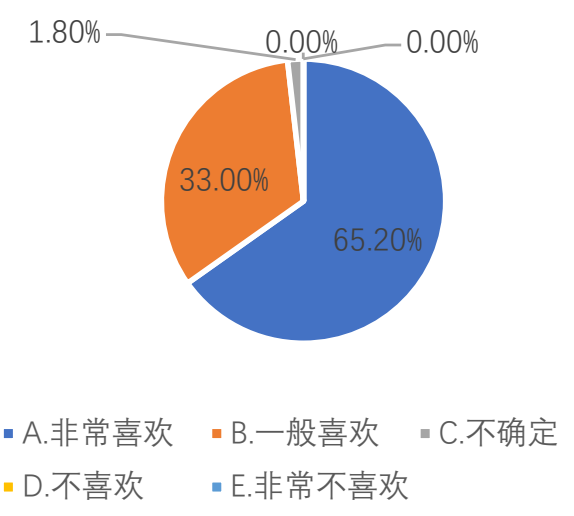

图 1 坤甸华人零零后对春节的态度

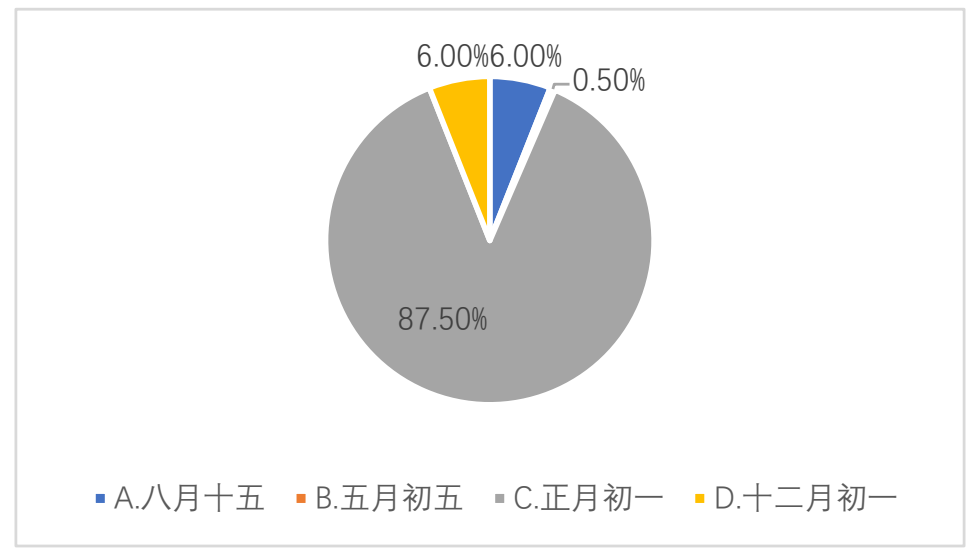

图 2 坤甸华人零零后对春节日期的了解

在忌讳的传承方面, $46.4 \%$ 的受访者认为非常需要传承, $44.6 \%$ 的受访者认为 一般需要传承, 这说明坤甸华人零零后对春节忌讳的认同度也是较高的 (见图 3 )。

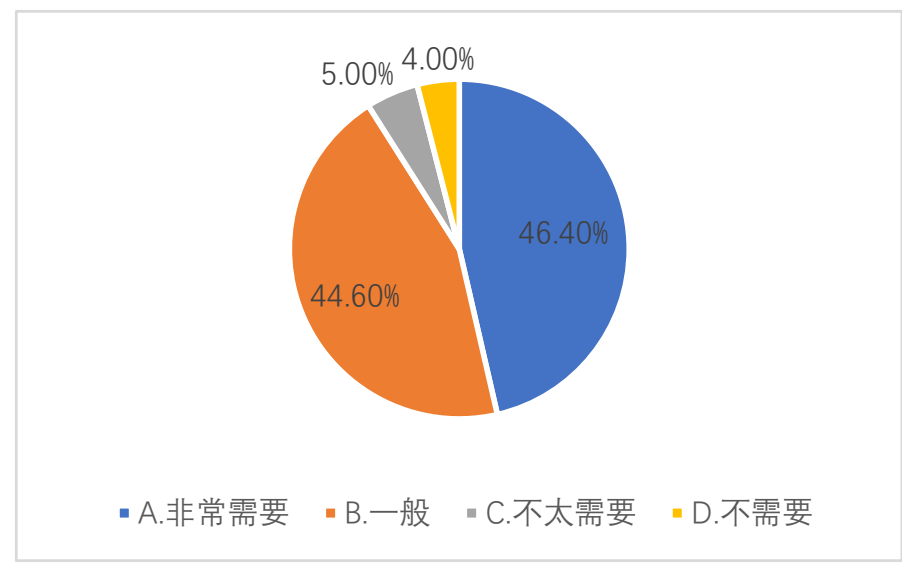

图 3 坤甸华人零零后对春节忌讳的认同

\section{3 对春节习俗与忌讳并没有太多了解}


在忌讳方面, 零零后群体的了解则要低很多。在了解方面, $36.6 \%$ 的受访者 表示自己了解, 大部分 51. 8\%的受访者表示自己只了解一点基本常识, 甚至还有 相当一部分 00 后受访者表示自己根本不了解春节的习俗或者忌讳（见图 4)。在 这样的背景下, 表示自己非常相信春节忌讳的仅占 $14.3 \%, 78.6 \%$ 的受访者态度 一般 (见图 5)。而认为春节需要一定的习俗与忌讳来体现的仅占 $43.8 \%$, 认为一 般需要的占比 $42.9 \%$, 还有近 $15 \%$ 的受访者认为春节不需要习俗或者忌讳来体现 (见图 6)。

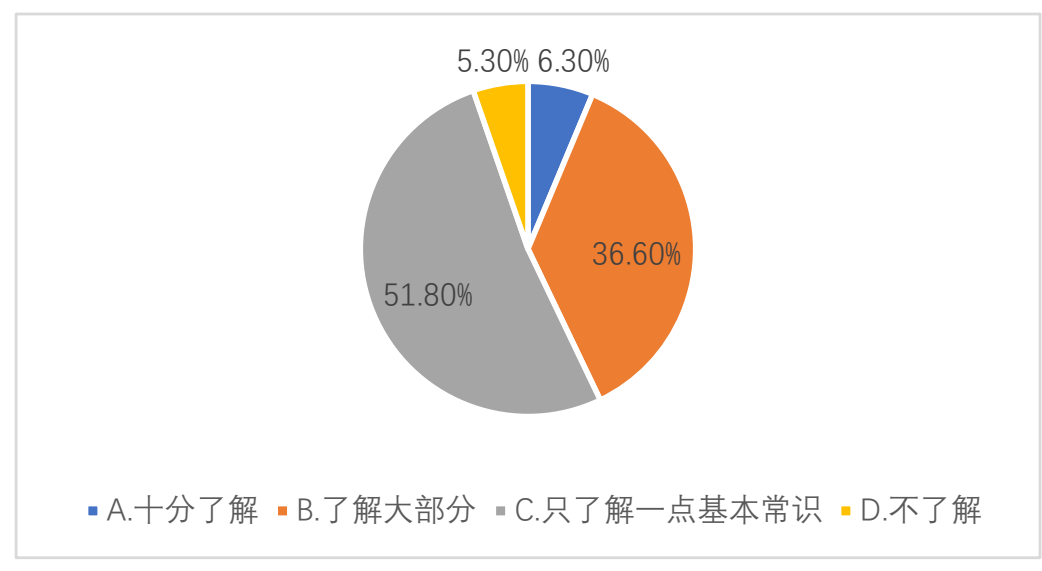

图 4 坤甸华人零零后对春节习俗与忌讳的了解

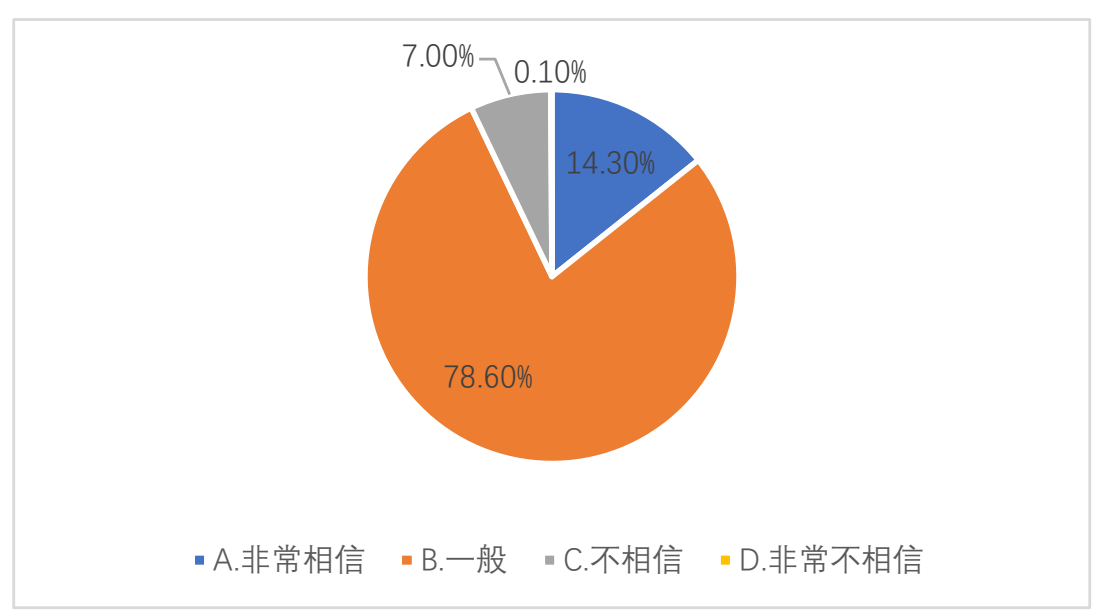

图 5 坤甸华人零零后对春节忌讳的信赖度 


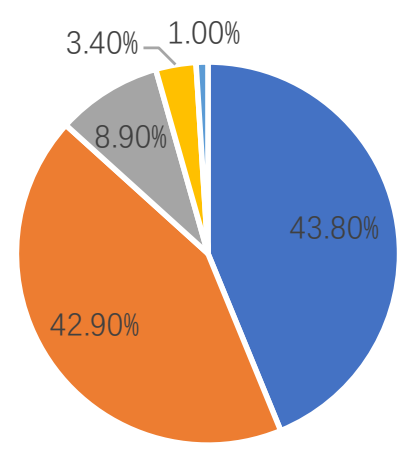

- A. 需要 - B. 一般需要 - C. 无所谓 - D. 一般不需要 - E. 非常不需要

图 6 坤甸华人零零后对春节忌讳存在必要性的看法

正是由于零零后华人对春节习俗和忌讳的认识不高, 在问到哪些不是春节的 忌讳时, $36.6 \%$ 的人回答拿红包, $45.5 \%$ 的人回答放烟花, $64.3 \%$ 的人回答吃饺子, 占比都不是很高, 这说明受访者中认为这些事情是忌讳的大有人在（见图 7)。

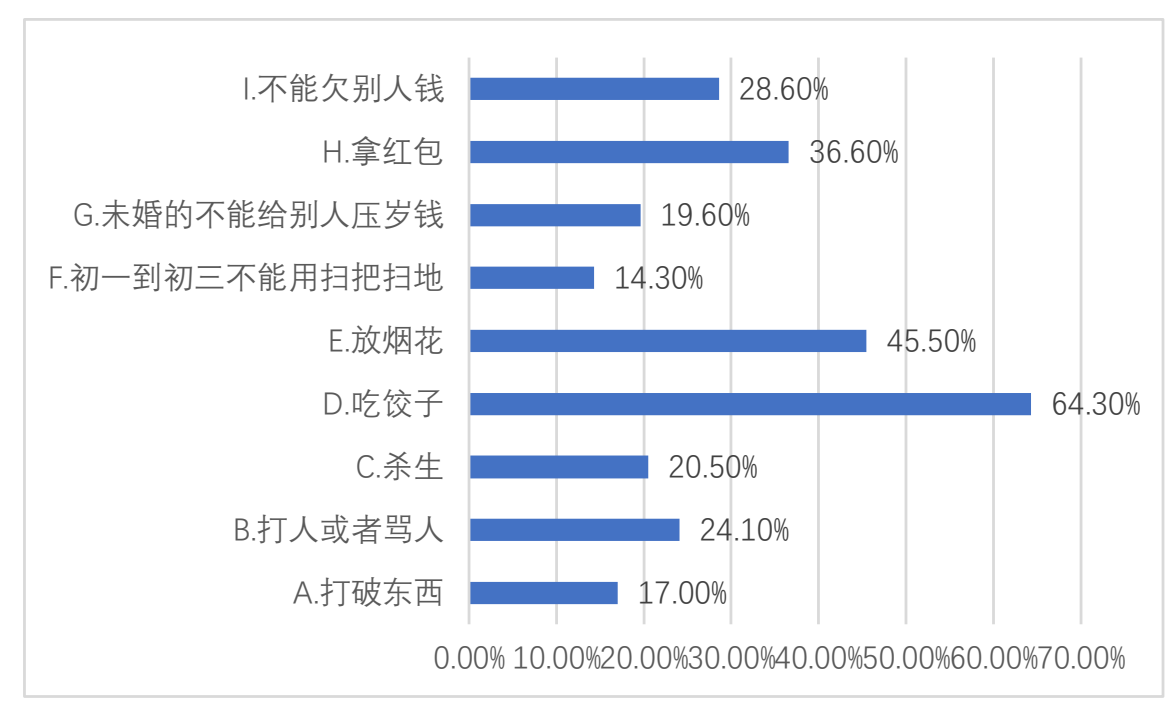

图 7 坤甸华人零零后对春节忌讳的认知

\section{4 感性认识较强, 理性认识偏弱}

所谓感性的认识是指人们在认识事物的过程中, 通过自己的感官在自己的思 维中直接认识客观事物并形成与之对应的感觉或者印象的过程。换言之, 感性认 识就是春节习俗和忌讳在坤甸华人零零后中留下的最直观的印象。在问到受访者 哪些不是春节的习俗时, 93\%的受访者回答吃月饼, $67 \%$ 的受访者回答划龙船, $65.2 \%$ 
的受访者回答吃粽子 (见图 8)。

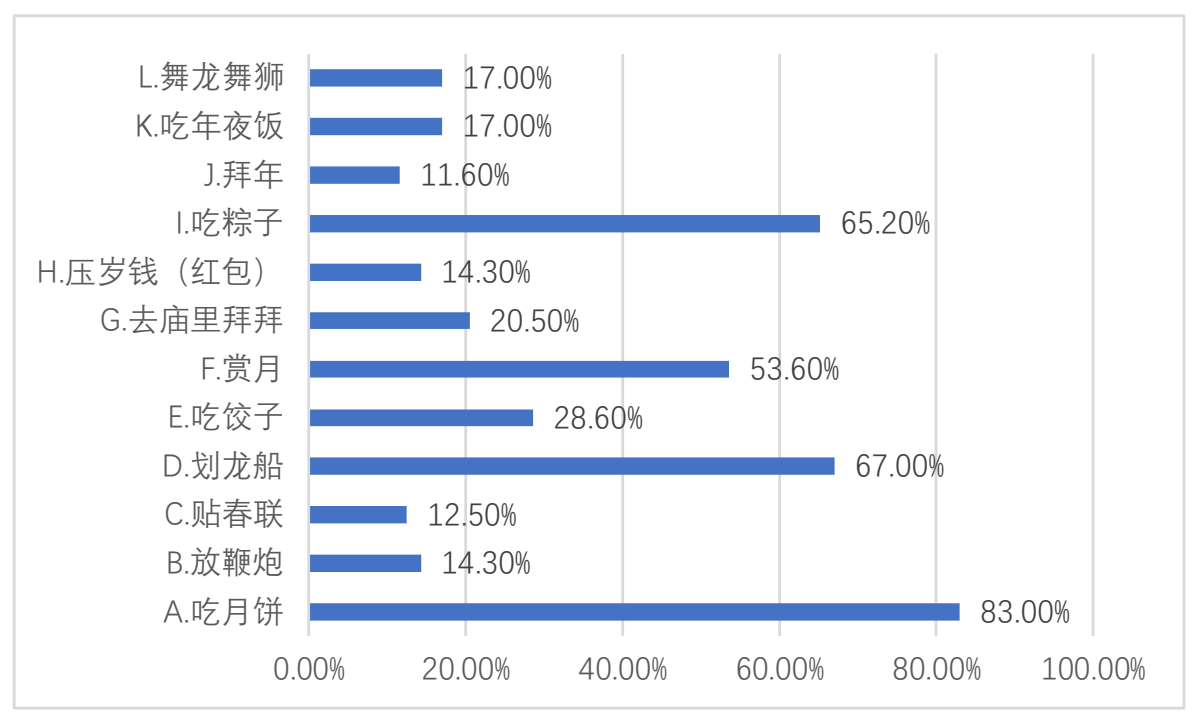

图 8 坤甸华人零零后对春节代表符号的认知

而在问到哪些不是春节忌讳的符号时, $40.2 \%$ 的受访者回答睡午觉, 另有相 同比例的受访者回答是红纸, 可见零零后受访者对春节忌讳的感性认知同样是较 强的（图 9)。

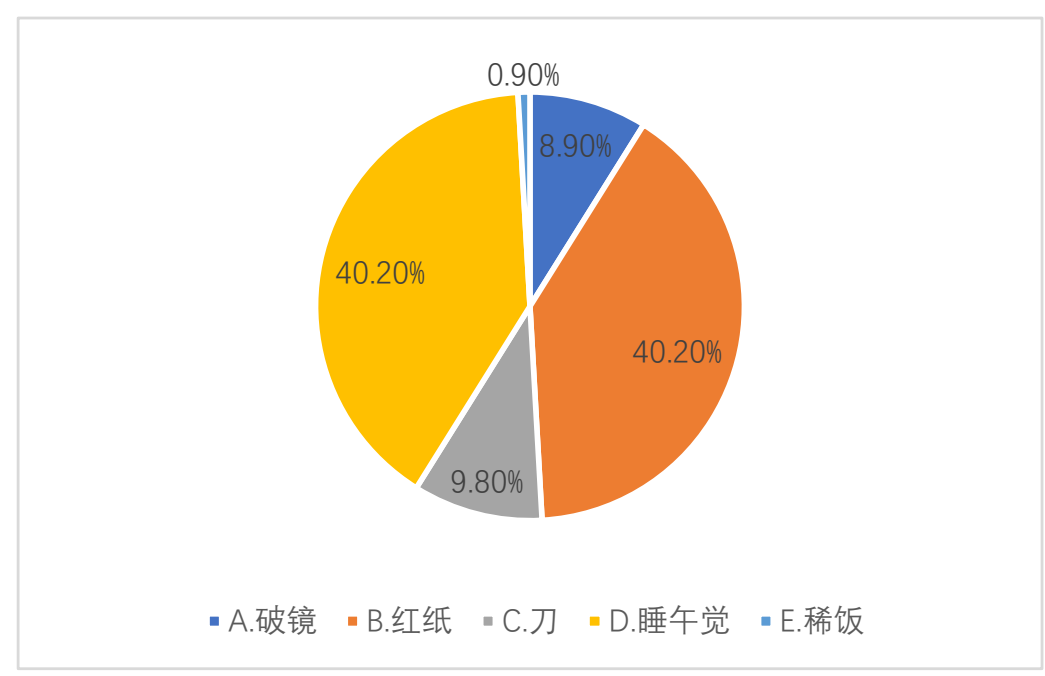

图 9 坤甸华人零零后对春节忌讳符号的认知

理性的认识是在感性认识的基础上, 对物体表象的深化所得出的一种系统的 认知, 这种认知不会受到表象的影响, 是对感性认知的升华。大众对于某一事物 的理性认识通常表现为对该事物的态度。在问及零零后受访者认为春节习俗与忌 
讳对过年有什么意义时, 回答 “可以加深对春节文化内涵的理解” 的人数占比仅 为 $47.3 \%$, 尚不足半数, $32.1 \%$ 的受访者回答 “可以更好的表达人们对春节的感 情”，17.9\%的受访者回答 “可以增加过年的节日氛围” (见图 10)。而事实上， 无论是“可以增加过年的节日氛围”还是“可以更好的表达人们对于春节的情感” 都只是对春节习俗和忌讳的表面关注，实际上还是属于感性认知，只有 “可以加 深对春节文化内涵的理解” 是表明零零后对春节习俗和忌讳的认识达到了更深的 层次, 属于理性认识。

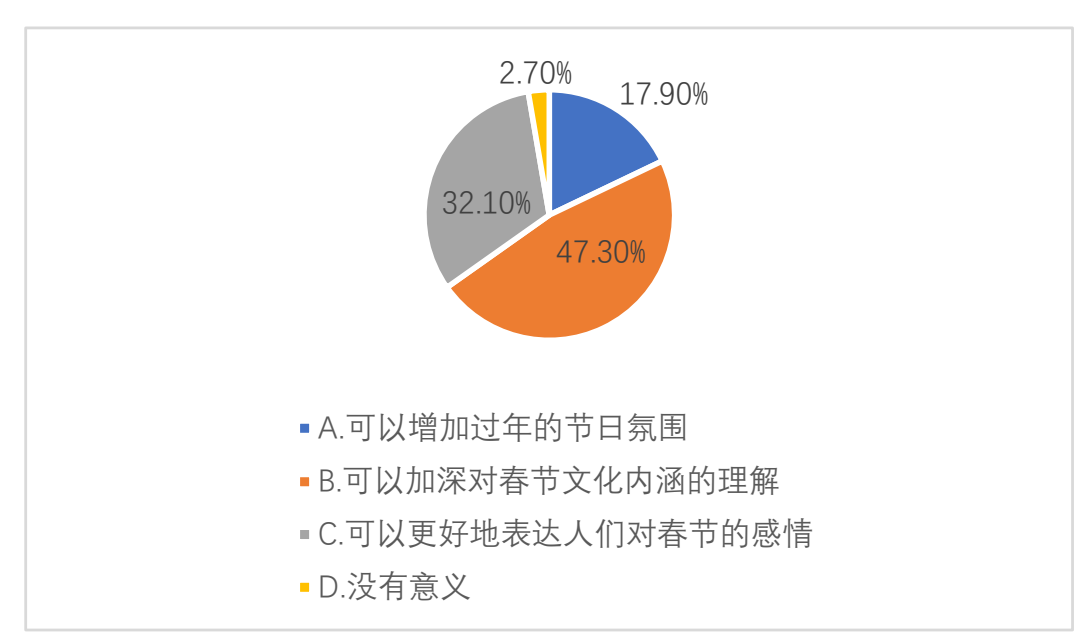

图 10 坤甸华人零零后对春节习俗和忌讳的意义认识

当然, 在问到受访者对春节文化里的习俗和忌讳的具体含义认知多少时, 高 达 73. $2 \%$ 的受访者表示自己只是一般了解, 而 19.6\%的受访者表示自己不确定 (见 图 11)。这也反映出了零零后对春节习俗还是感性认识加强, 理性认识偏弱。

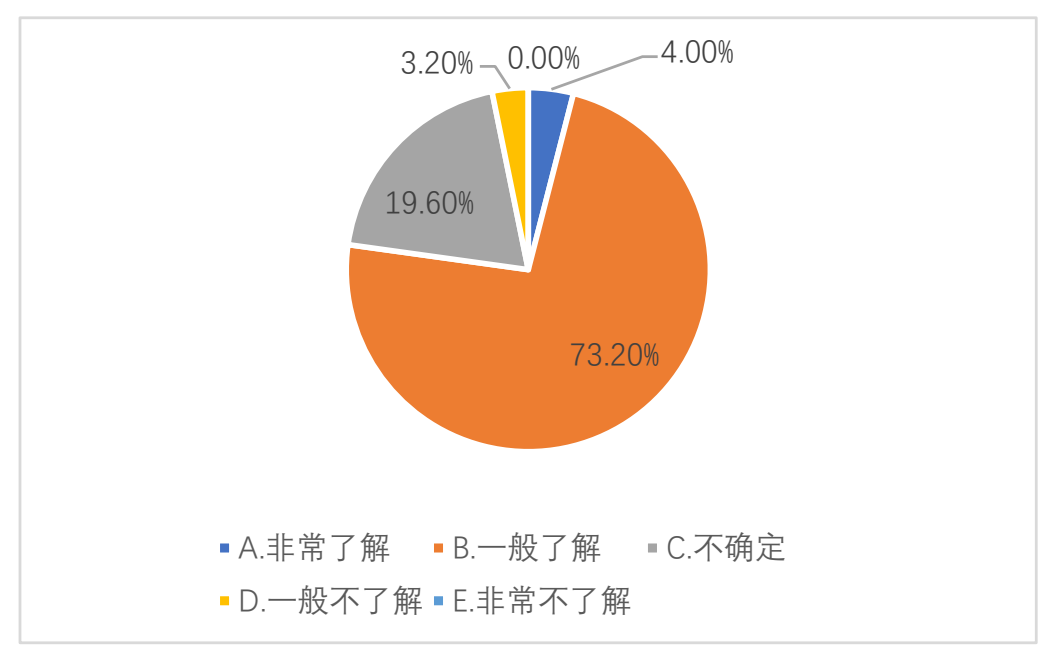

图 11 坤甸华人零零后对春节习俗与忌讳的具体含义认识 


\section{5 认识渠道单一, 主体性较差}

在问及零零后受访者对春节计划的认知主要来源于哪一方面时, 接近 $80 \%$ 的 受访者都是回答来自于自己的父母, 媒体、学校或者自主学习认知带来的认识都 比较少（见图 12）。同样在问到受访者可以通过什么途径加深对春节习俗与忌讳 的认识和理解时, 占比最多的回答是从家长途径来加深理解和认识, 占比约为 $33.9 \%$ 。其次是通过学校开设的课程或者社团的参与占比 $28.6 \%$, 再次是自身学 习与参与占比 $17.9 \%$ (见图 13)。

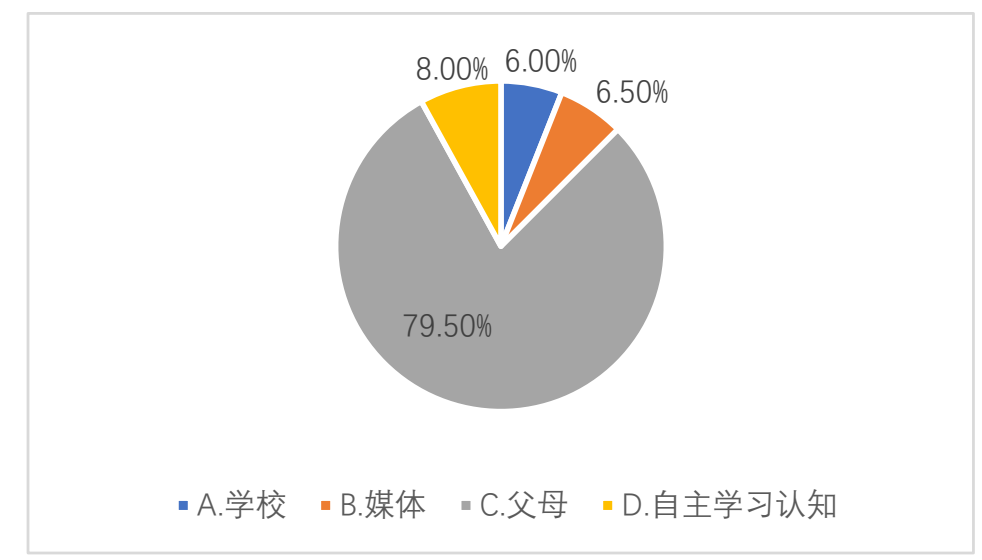

图 12 坤甸华人零零后了解春节习俗与忌讳的渠道

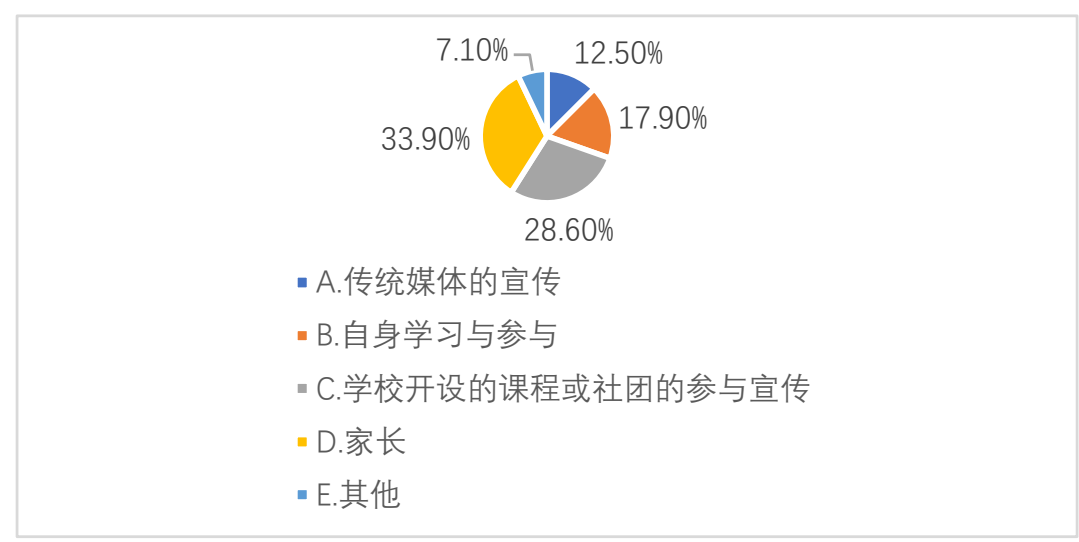

图 13 坤甸华人零零后加深对春节习俗与忌讳的认识和理解的途径

仅从认知渠道的角度来看, 坤甸华人零零后对春节习俗与忌讳的认识渠道其 实是比较单一的, 无论是对于春节这一习俗本身, 还是对春节中的忌讳, 大部分 受访者的认识都是来源于自己的父母。当然这也合乎情理, 大部分 00 后都还没 
有成年, 因而对于春节习俗和忌讳的认识主要来自于父母的言传身教以及从小的 耳濡目染。但是与此同时, 零零后群体也基本拥有了自己的思维能力, 然而通过 自主学习认知春节这一习俗的占比并不高, 这说明在面对春节习俗和忌讳上, 零 零后受访者的主体性或者能动性还有待提升。

\section{6 行为认同度较高, 持有开放态度}

尽管大部分的人都认为春节的年味变淡了, 但是实际上华人零零后中对春节 当前的年味还是比较认同的, 8. 9\%的受访者表示自己非常喜欢现在的年味, 53. $6 \%$ 的受访者表示自己一般喜欢现在的年味（见图 14）。

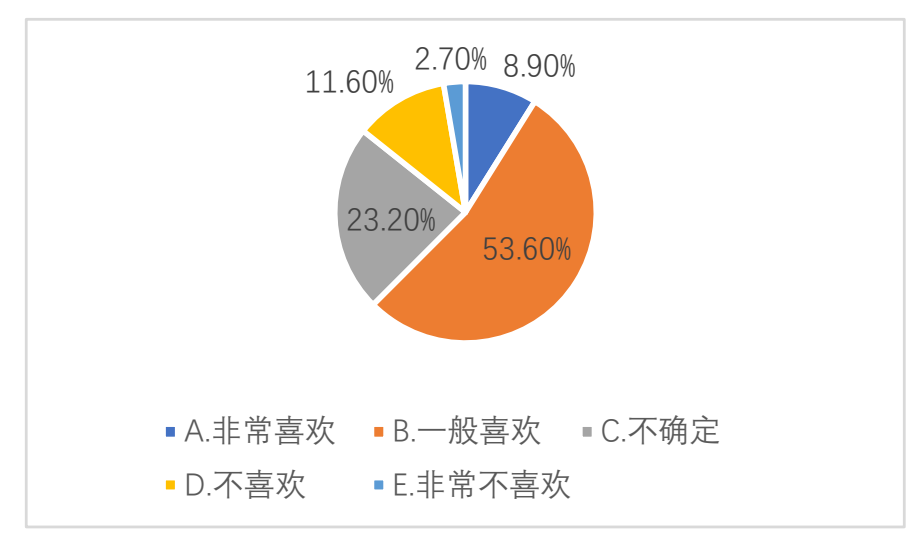

图 14 坤甸华人零零后对现代年味的看法

在对春节习俗和忌讳的认识上, 零零后华人既有对原有的春节文化的继承, 也有对春节文化的突破。例如在过春节的方式上，接近 90\%的受访者表示自己愿 意回家与家人一起团圆, 这也正是中国传统的过春节的方式, 阖家团圆是一户家 庭春节最好的期望 (见图 15)。但是随着时代的发展, 也有越来越多的零零后华 人愿意通过通讯软件或者打电话这种新的形式来拜年, 传统春节文化与现代科技 文化并存（见图 16）。

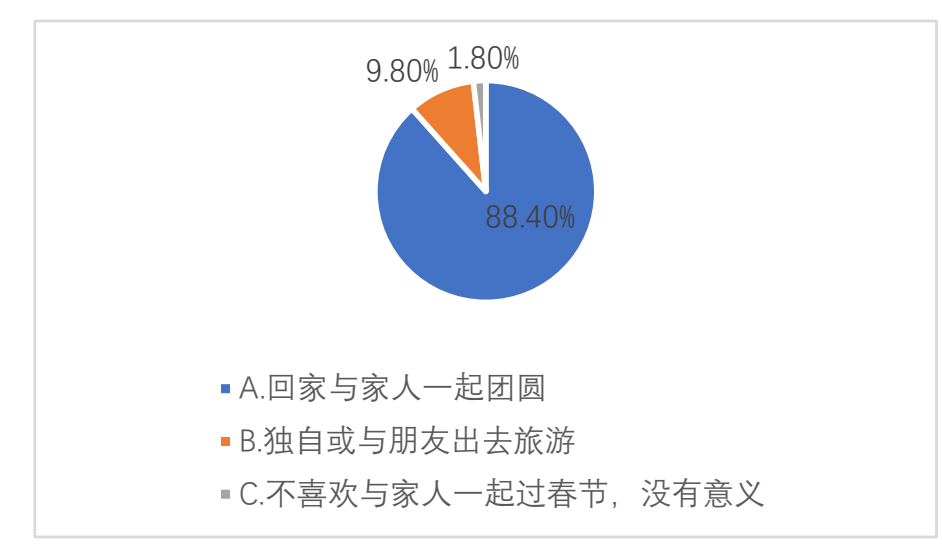


图 15 坤甸华人零零后过春节的方式

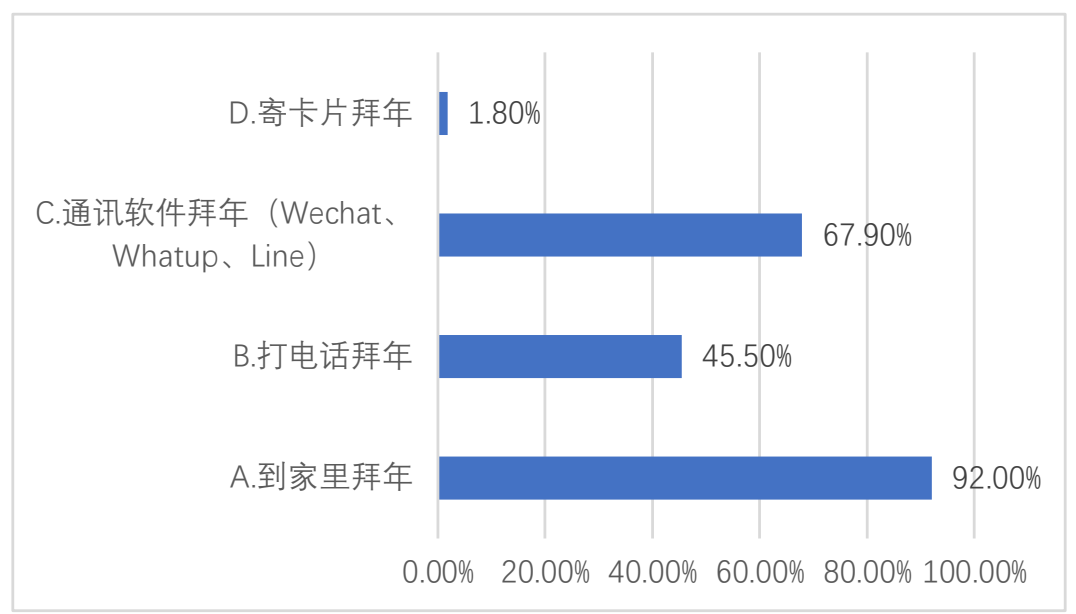

图 16 坤甸华人零零后拜年的方式

正是因为华人零零后对春节的习俗和忌讳持有开放的态度, 在问到受访者希 望未来的春节习俗和忌讳朝着哪个方向发展时, 33. 9\%的受访者表示该怎样就怎 样，没什么需要改变; $26.8 \%$ 的受访者表示按照传统加大宣传力度; $23.2 \%$ 的受访 者表示找到适合印尼国情与社会发展方式，过带有印尼特色的春节; 还有 $16.1 \%$ 的受访者表示与时俱进, 向国外节目借鉴, 在形式上有适当创新, 取其精华, 去 其糟粕（见图 17）。

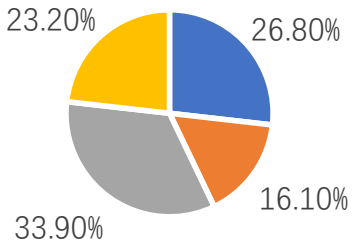

- A. 遵照传统, 加大宣传力度

- B.与时俱进, 向国外节日借鉴, 在形式上要适当创新, 取其精华, 去 其糟粕

- C.该怎样就怎样, 没什么需要改变

- D. 找到适合印尼国情与社会发展方式，过带有印尼特色的春节

图 17 坤甸华人零零后对春节习俗与忌讳发展的看法 


\section{四 文化认同一一印尼华人的血脉传承}

春节是中华民族的象征，代表着中华民族先民们对生活的态度，也是民族情 感的外化。在中华文化中, 春节其实就是团圆的日子, 是一种团圆的文化, 更是 中华儿女们对未来的祈祷和憧憬。即便是对于定居国外多年的印尼华人而言, 这 种团圆意识也是根植于他们的心中。因而即便部分华人零零后对春节习俗与忌讳 并没有太多了解、感性认识较强, 理性认识偏弱, 春节的习俗和忌讳仍旧停留在 他们的心中, 到了春节这个特殊的日子零零后的华人们也会再次从父母处接受中 华文化的熏陶, 过去与现在就是通过这样一种周而复始的节日得以交汇, 文化的 血脉就是通过周而复始的节日来得到强化, 成为了印尼华人心中的文化认同。

\section{五 差序格局一一印尼华人的文化实践}

关于印尼华人的文化认同, 笔者认为其根源来自于中国社会的差序格局。中 国著名的社会学家费孝通先生在其著作《乡土中国》中提出了差序格局的概念, 用以解释中国人的社交文化。差序格局认为社会中的每个个体都如同投入水中的 石子, 由此泛起了一圈又一圈的涟渏, 而这些涟渏由近到远分别是血缘、地缘、 经济水平、政治地位、知识文化水平，人与人之间的亲疏远近由这种差序格局来 进行确定。孔子所说的 “君君臣臣父父子子”也正是这样一种差序格局的反应。 当个体的 “石子” 溅起涟猗时, 受影响最大的必然首先是与其由亲缘关系的人, 地缘关系、经济关系、政治关系紧随其后。在这样一种伦理格局的背景下, 印尼 华人尽管没有去过中国, 却接收到了与自己存在血缘关系的长辈的直接影响, 成 为长辈们泛起的第一道 “涟渏”。而正是有了差序格局的存在, 印尼华人才能对 中华文化有深刻的认同感, 外化为对春节机会与习俗的接受, 内化为自己的血脉 传承。

\section{六 结语}

在诸多世界文化中，中华文化都是一个特例，从未有文化能够像中华文化一 样源远流长, 也从未有文化能够让其传人在身居异国他乡之时仍旧能够传承不断, 严格遵循各种节日的习俗和忌讳。本文以坤甸华人零零后作为研究对象, 了解了 零零后华人群体对春节习俗与忌讳的认识, 从研究结果来看, 首先坤甸华人零零 
后对春节习俗和忌讳有较强的认同感但是对春节习俗与忌讳并没有太多了解; 其 次坤甸华人零零后对春节习俗与忌讳的感性认识较强, 理性认识偏弱; 再次, 坤 甸华人零零后对春节习俗与忌讳的认识渠道单一, 主体性较差; 最后坤甸华人零 零后对春节习俗与忌讳的行为认同度较高, 持有开放态度。 


\section{参考文献}

[1] 陈虹娇. 南非中文专业大学生汉语学习动机与文化认同研究 [D]. 暨南大 学, 2018 .

[2]费孝通. 乡土中国：修订本 $[M]$. 上海人民出版社， 2013.

[3] 胡翊. 二战后印尼华人经济的发展状况、影响因素及贡献 [D]. 华中师范大 学, 2017.

[4] 黄显. 印尼华裔青少年对中华文化的认同及其对汉语学习的影响 [D].广西 师范大学, 2012 .

[5] 姜瑛. 菲律宾主流中学学生汉语学习动机与中华文化认同相关度研究 [D]. 福建师范大学, 2018.

[6] 祁琳. 泰国华裔青少年对中华文化认同及影响因素的调查研究 [D]. 山东师 范大学, 2018 .

[7] 沈玲. 印尼华人家庭语言使用与文化认同分析一一印尼雅加达 500 余名新生 代华裔的调查研究 $[J]$. 世界民族, 2015 (05)

[8] 王爱平. 印尼华裔青少年的身份认同与国家认同一一华侨大学华文学院(集 美) 印尼华裔学生的调查研究 $[J]$. 武汉大学学报 (哲学社会科学版), 2006 (02)

[9] 王凯南. 日本汉语学习者的文化认同研究 [D]. 内蒙古师范大学, 2018 .

[10］杨子健. 在坙来华留学生跨文化适应与中华文化认同的相关研究 [D]. 广 西大学, 2018.

[11］吴白露. 中国春节文化海外传播策略研究 [D]. 华中科技大学博士学位论 文, 2014 .

[12] 张小倩.二十一世纪以来印尼华人 “再华化” 现象研究 $[J]$. 世界民 族, $2016(01)$

[13] 张永慧. 中国人对节日的认知表征和行为研究 [D]. 曲阜师范大学硕士学位论 文. 2014 .

\section{DATA PENULIS（作者简介）}


Jurnal Cakrawala Mandarin

Asosiasi Program Studi Mandarin Indonesia

Vol.4, No.1, April 2020: P25-41

E-ISSN: 2579

$-4906$

Name : Lysa Lho（何利冰）

Country : Indonesia（印度尼西亚）

University : Sekolah Tinggi Harapan Bersama（共同希望语言学院）

Hp : $\quad 089647534753$

Email : 1ysa_ho@foxmail.com 